\title{
Abnormal placentation in caesarean scar ectopic pregnancy
}

\author{
Melissa J Chen, ${ }^{1}$ Eric C Huang, ${ }^{2}$ Melody Y Hou ${ }^{1}$
}

'Department of Obstetrics and Gynecology, University of California, Davis School of Medicine, Sacramento, California, USA

${ }^{2}$ Department of Pathology, University of California, Davis, Sacramento, California, USA

\section{Correspondence to} Dr Melody Y Hou, myhou@ucdavis.edu

Accepted 17 October 2016
CrossMark

To cite: Chen MJ,
Huang EC, Hou MY. BMJ
Case Rep Published online:
[please include Day Month
Year] doi:10.1136/bcr-2016-
217311

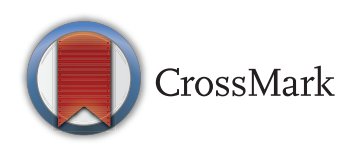

217311

\section{DESCRIPTION}

A multiparous woman aged 34 years with a prior low transverse caesarean delivery presented at 12 weeks gestation for nuchal translucency screening. She had an unremarkable ultrasound study at 8 weeks gestation. Although asymptomatic at her screening, the patient had imaging findings suspicious for a caesarean scar ectopic, including loss of myometrial border between the placenta and uterine serosa on her ultrasound (figure 1A) and MRI examinations (figure 1B). The patient was counselled on her options, including continuing the pregnancy with further interventions at the time of delivery, medical management with intra-amniotic potassium chloride and systemic methotrexate, and hysterectomy. Since she had completed child bearing, she chose surgical treatment. A total abdominal hysterectomy was performed without complication. Intraoperative findings included a 14-week sized uterus with placenta implanting and penetrating the lower uterine segment (figure 2). Histology revealed placenta increta with villi extending to $0.5 \mathrm{~mm}$ from the uterine serosa (figure 3). Her recovery was uneventful.

Caesarean delivery is associated with various complications, including abnormal placentation and caesarean scar pregnancies in subsequent gestations. ${ }^{1}$ A theory exists that caesarean scar pregnancies and abnormal placentation may be manifestations of the same disease process. ${ }^{2}{ }^{3}$ Our case provides further histological evidence of placental increta after ultrasound diagnosis of caesarean scar pregnancy. With this knowledge, patient

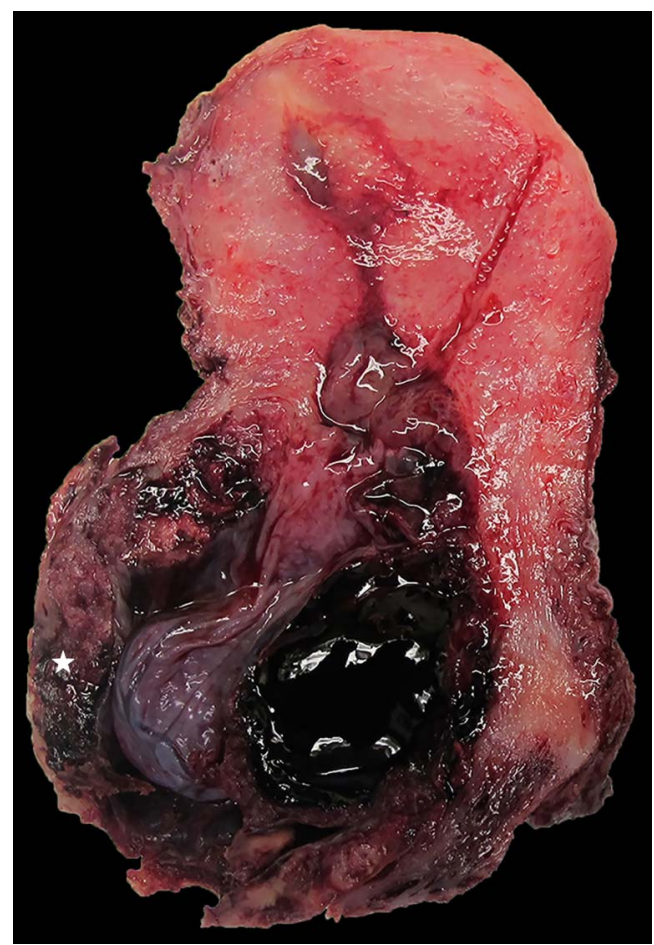

Figure 2 Bivalved uterus with caesarean scar pregnancy. Note the placental implantation and thinning of the anterior lower uterine segment (white star).

counselling regarding caesarean scar pregnancies should reflect that expectant management will likely result in abnormal placentation and its

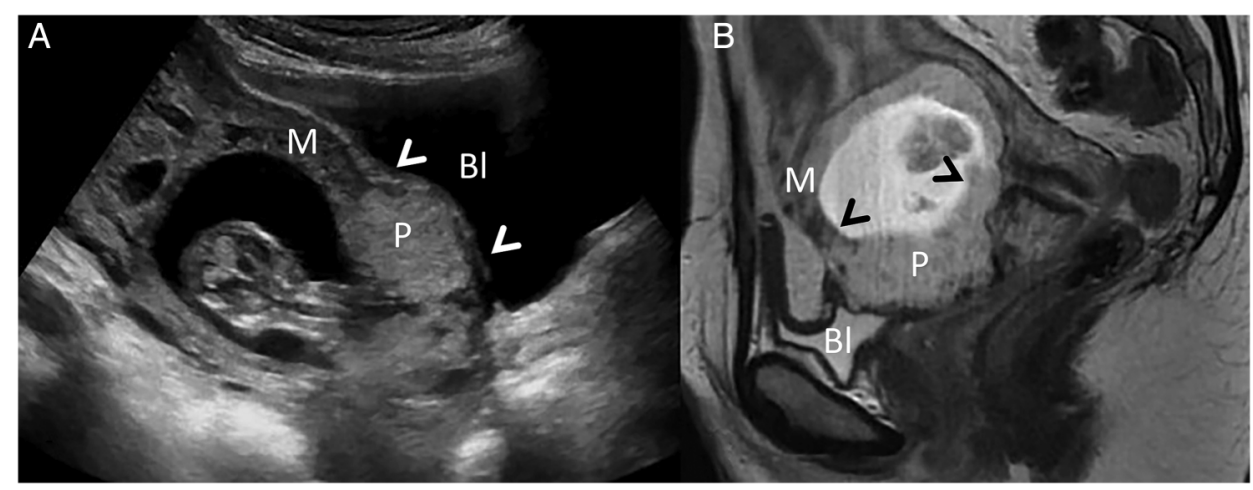

Figure 1 Loss of the myometrial border $(M)$ between the placenta $(P)$ and uterine serosa indicated with white arrowheads on ultrasonography (A) and black arrowheads on MRI (B), with uterine serosa and bladder (BI) interface intact. 


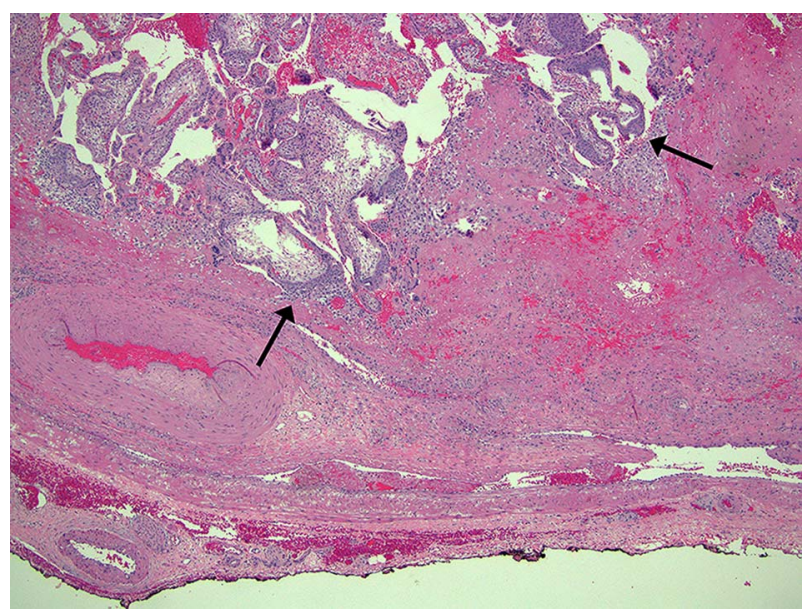

Figure 3 Placental villi (black arrows) penetrating the myometrium and extending to $0.5 \mathrm{~mm}$ from the serosa (inked black).

associated complications at the time of delivery. Prompt diagnosis and treatment of caesarean scar pregnancies can minimise maternal morbidity and mortality.

Contributors MJC wrote and revised the manuscript. ECH created the pathology images, wrote the pathology description and revised the manuscript. MYH conceived and revised the manuscript.

\section{Learning points}

- Caesarean scar pregnancies and abnormal placentation are likely manifestations of the same disease process; accordingly, patients should be counselled that expectant management will likely result in complications related to abnormal placentation, such as hysterectomy, at the time of delivery.

- Prompt diagnosis of caesarean scar pregnancy is important for early treatment to minimise maternal morbidity.

Competing interests None declared.

Patient consent Obtained.

Provenance and peer review Not commissioned; externally peer reviewed.

\section{REFERENCES}

1 Timor-Tritsch IE, Monteagudo A. Unforeseen consequences of the increasing rate of cesarean deliveries: early placenta accreta and cesarean scar pregnancy. A review. Am J Obstet Gynecol 2012;207:14-29.

2 Timor-Tritsch IE, Monteagudo A, Cali G, et al. Cesarean scar pregnancy is a precursor of morbidly adherent placenta. Ultrasound Obstet Gynecol 2014;44:246-53.

3 Sinha P, Mishra M. Caesarean scar pregnancy: a precursor of placenta percreta/ accreta. J Obstet Gynaecol 2012;32:621-3.

Copyright 2016 BMJ Publishing Group. All rights reserved. For permission to reuse any of this content visit

http://group.bmj.com/group/rights-licensing/permissions.

BMJ Case Report Fellows may re-use this article for personal use and teaching without any further permission.

Become a Fellow of BMJ Case Reports today and you can:

- Submit as many cases as you like

- Enjoy fast sympathetic peer review and rapid publication of accepted articles

- Access all the published articles

- Re-use any of the published material for personal use and teaching without further permission

For information on Institutional Fellowships contact consortiasales@bmjgroup.com

Visit casereports.bmj.com for more articles like this and to become a Fellow 